\title{
A Transverse Tri-Anastomotic Conjoined Nerve Root Discovered During a Lumbar Discectomy L5-S1
}

\author{
Keyvan Mostofi, b, e, Christophe Hardit ${ }^{\mathrm{c}}$, \\ Reza Karimi Khouzani ${ }^{\mathrm{d}}$
}

\begin{abstract}
Conjoined nerve root is an abnormality of nerve root. The incidence is between $0.3 \%$ and $30 \%$. It arises during the fetal development of spine. The abnormality can be asymptomatic or produce lumbar back pain or radiculalgia. Sometimes it is diagnosed during spine surgery or in post mortem autopsy. Lack of diagnosis of conjoined nerve root may lead to surgical procedure failure and increase neurological injury. We present a case of a 52-year-old man who was operated for a lumbar discectomy with mixed L5 and S1 radiculopathy with a rare type of conjoined root nerve in shape of three anastomotic nerve roots.
\end{abstract}

Keywords: Conjoined nerve root; Lumbar back pain; Radiculopathy

\section{Introduction}

Conjoined nerve root is an anomaly of nerve root [1]. The incidence is estimated about $6 \%[1,2]$. In this anomaly, the nerve root emerges at an abnormal level or from an anastomotic branch.

The most commonly reported level is L5-S1 [3]. Lack of diagnosis of this anomaly can lead to surgical procedure failure and increase neurological injury. Consequently, preoperative diagnosis of this anomaly is very important to avoid inadvertently damaging the nerve root. Sometimes it may manifest with low back pain or radiculalgia but it can be discovered incidentally during surgery. MRI is currently the best method available to diagnosis.

\footnotetext{
Manuscript accepted for publication February 17, 2017

${ }^{a}$ Clinique Bel Air, 138, Avenue de la Republique, 33000 Bordeaux, France ${ }^{b}$ Department of Neurosurgery, Centre Clinical de Soyaux Chemin de Fregeneuil, 16800 Soyaux, France

'Department of Radiology, Centre Clinical de Soyaux Chemin de Fregeneuil, 16800 Soyaux, France

${ }^{\mathrm{d} D e p a r t m e n t}$ of Neurosurgery, International Neurosciences Institut, Hanover, Germany

${ }^{\mathrm{e} C}$ Corresponding Author: Keyvan Mostofi, Clinique Bel Air, 138, Avenue de la Republique, 33000 Bordeaux, France. Email: keyvanmostofi@yahoo.fr
}

\section{Case Report}

We report a case of a 52-year-old male patient who presented a mixed L5 and S1 radiculopathy. He had pain for more than 8 months. Conventional therapy was ineffective. A peridural infiltration failed too.

The lumbar MRI demonstrated an L5-S1 disc protrusion (Figs. 1and 2).
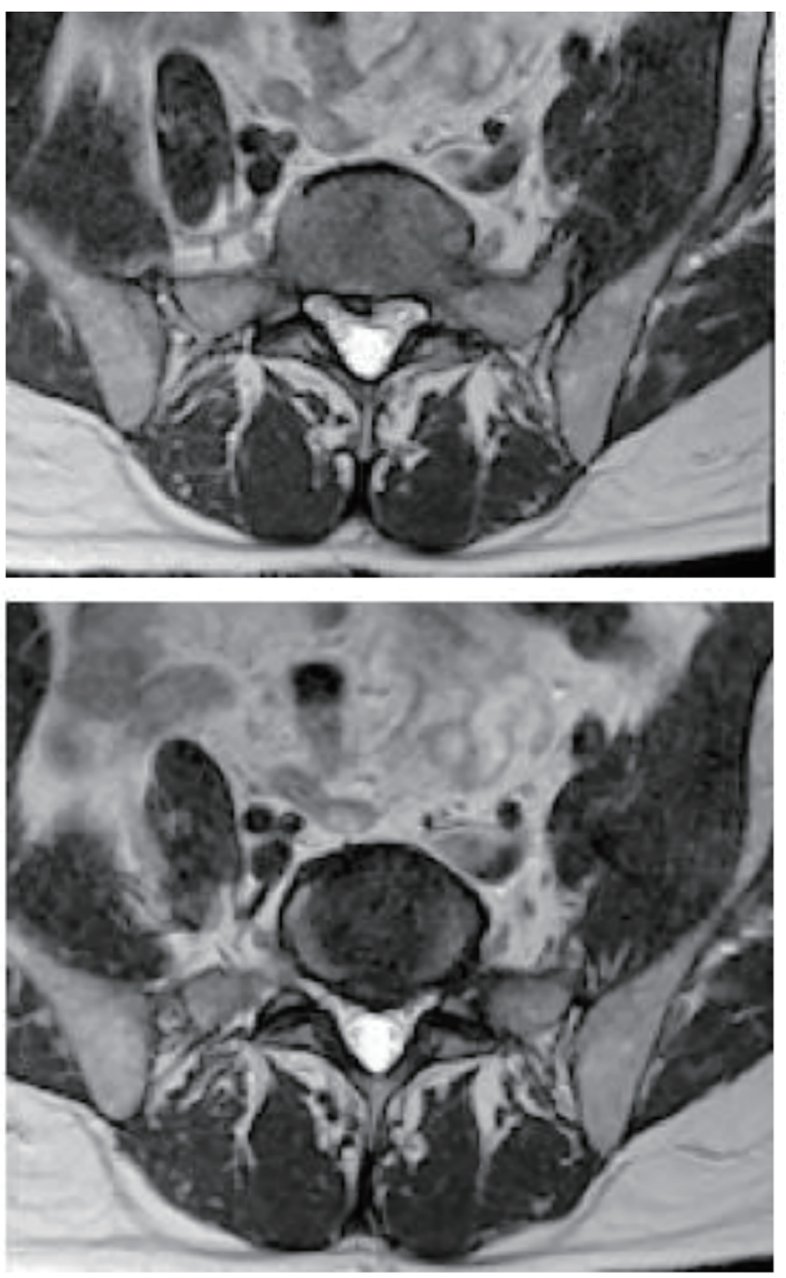

Figure 1. T2 axial MRI images show disc protrusion in L5-S1 level. 


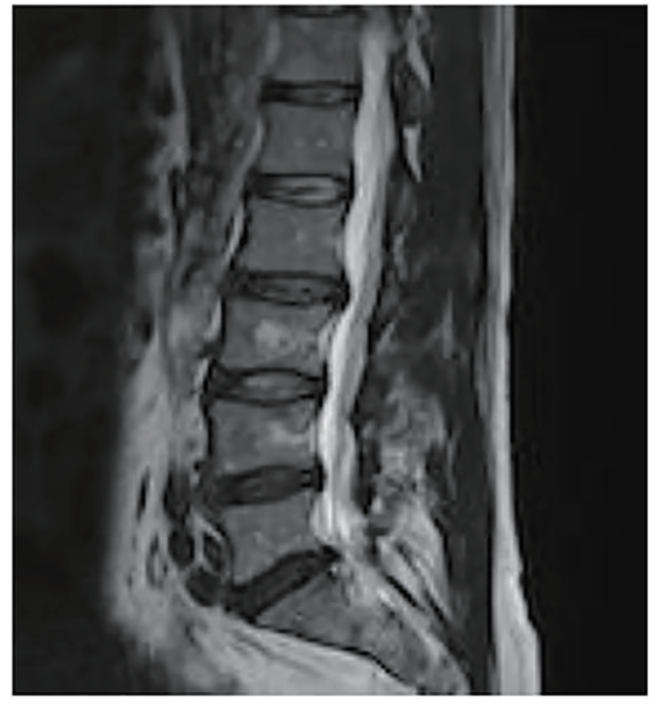

Figure 2. T2 sagittal MRI image shows disc protrusion in L5-S1 level.

He was operated by L5-S1 endoscopic discectomy. The $\mathrm{L} 5$ and $\mathrm{S} 1$ radiculopathys were relieved after surgery. The peroperative data showed an conjoined nerve root of L5 and S1.

There were three anastomotic nerve roots in which adjacent nerves were connected in the form of a transverse anastomosis (Fig. 3). The patient was discharged the day after surgery. The clinical exam was normal the day of check-up and 6 weeks after surgery.

\section{Discussion}

According to Artico et al, the incidence of nerve root anomalies is between $0.3 \%$ and $30 \%$ [ 4 ].

The anomalies arise during the fetal development of spine [5]. Cannon et al presented a first classification of nerve root anomalies [6] and Neidre and MacNab modified this classification of four types of abnormalities [2, 7]. The first type is the conjoined nerve root emerging from a common dural sheath, quiting the spinal canal through the intervertebrale foramen. The second type is described as two nerve roots exiting through the same intervertebral foramen. The third type consists of a group of anastomotic nerve roots in the form of a transverse or vertical anastomosis. The fourth type invovles all mixed cases of the above types.

MRI is the best imaging for diagnosis of conjoined nerve root anomalies [2]. The coronal T2-weighted MR image is more sensible [8]. Bottcher et al proposed application of gadolinium contrast media in MRI for better identification [2]. More generally, patients present low back pain or radiculalgia [9]. They may show other symptoms like weakness, numbness and another kind of paresthesia $[6,7,10]$. Nerve root anomalies can be confused or may be contemporaneous with disc herniation. In these circumstances, the sciatic pain should be treated with particular caution, particularly if a surgery is indicated. It is, however, considered a last resort and used only when other methods have failed.

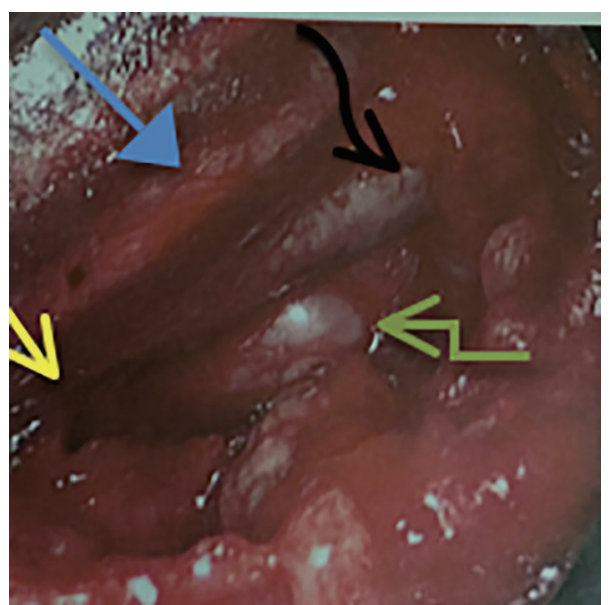

Figure 3. Perioperative image demonstrates tri-anastomotic transverse nerve roots. Yellow arrow shows emergence of the nerve roots from dural sheath. Blue, black and green arrows show three anastomotic nerve roots.

\section{Conflicts of Interest}

The authors declare that they have no conflicts of interest.

\section{References}

1. Oh CH, Park JS, Choi WS, Choi E, Ji GY. Radiological anatomical consideration of conjoined nerve root with a case review. Anat Cell Biol. 2013;46(4):291-295.

2. Bottcher J, Petrovitch A, Soros P, Malich A, Hussein S, Kaiser WA. Conjoined lumbosacral nerve roots: current aspects of diagnosis. Eur Spine J. 2004;13(2):147-151.

3. Taghipour M, Razmkon A, Hosseini K. Conjoined lumbosacral nerve roots: analysis of cases diagnosed intraoperatively. J Spinal Disord Tech. 2009;22(6):413-416.

4. Artico M, Carloia S, Piacentini M, Ferretti G, Dazzi M, Franchitto S, Bronzetti E. Conjoined lumbosacral nerve roots: observations on three cases and review of the literature. Neurocirugia (Astur). 2006;17(1):54-59.

5. Bouchard JM, Copty M, Langelier R. Preoperative diagnosis of conjoined roots anomaly with herniated lumbar disks. Surg Neurol. 1978;10(4):229-231.

6. Cannon BW, Hunter SE, Picaza JA. Nerve-rootanomalies in lumbar-disc surgery. J Neurosurg. 1962;19:208-214.

7. Neidre A, MacNab I. Anomalies of the lumbosacral nerve roots. Review of 16 cases and classification. Spine (Phila Pa 1976). 1983;8(3):294-299.

8. Gomez JG, Dickey JW, Bachow TB. Conjoined lumbosacral nerve roots. Acta Neurochir (Wien). 1993;120(34):155-158.

9. Cail WS, Butler AB. Conjoined lumbosacral nerve roots. Diagnosis with metrizamide myelography. Surg Neurol. 1983;20(2):113-119.

10. Ogon M, Goebel WE, Trappe AE. [Recurrent sciatica caused by "conjoined nerve roots". Diagnosis, therapy, follow-up]. Nervenarzt. 1991;62(6):378-382. 